\title{
A CONFEDERAÇÃO DOS TAMOIOS, EPOPEIA MODELAR
}

\author{
THE TAMOIO CONFEDERACY, EXEMPLARY EPIC
}

Rafael Brunhara ${ }^{1}$

\begin{abstract}
Resumo: Este artigo propõe uma análise da Confederação dos Tamoios, buscando evidenciar que a concepção de Magalhães acerca do gênero épico está de acordo com o seu próprio programa poético e com um modelo de epopeia não devidamente considerado nas polêmicas sobre o poema. Nesse sentido, visa mostrar como o poema dialoga com preceitos de epopeia do passado ao mesmo tempo que pauta discussões futuras sobre o gênero.
\end{abstract}

Palavras-chave: Gonçalves de Magalhães, poesia épica, literatura clássica.

\begin{abstract}
This article proposes an analysis of the epic poem The Tamoio Confederacy, claiming that Magalhães' conception of the epic genre is in accordance with his own poetic program and with epic models not properly considered in the polemics about his work. Therefore, it aims to show how the poem dialogues with precepts of the epic of the past while guiding future discussions on the genre.
\end{abstract}

Keywords: Gonçalves de Magalhães, epic poetry, classical literature.

O título deste trabalho possivelmente soará a alguns como ingênuo ou provocador, a depender do entendimento que atribuímos ao termo "modelar". De que modo a Confederação dos Tamoios, trazida à lume num período em que a epopeia era um gênero poético em discussão, talvez à espera de reformulação, poderia ser modelar? Em outras palavras, a que modelo poderia se ligar, num período em que os modelos já são incertos ou objeto de questionamento? Nossa exposição propõe a hipótese de que a Confederação dos Tamoios pode ser chamada modelar justamente porque deflagra uma controvérsia que traz, ao centro do debate, as principais discussões concernentes ao gênero épico no século XIX. De certa forma, por ser uma epopeia no Romantismo, articulam-se na Confederação dos Tamoios questionamentos sobre o gênero épico em que se pode evidenciar seu presente, projetar seu futuro e retomar o seu passado. A Confederações dos Tamoios, assim, seja por causa dos elementos que mobiliza internamente, seja por causa da polêmica que gerou, demarca um lugar importante para o gênero épico nas letras brasileiras a partir do século XIX.

Argumentaremos que este lugar ocupado pelo poema se dá por causa de uma oscilação consciente ao longo de toda a obra de Gonçalves de Magalhães. O fundador oficial do Romantismo brasileiro ocupa um lugar de permeio, transicional, que alterna entre os moldes neoclássicos e os novos preceitos de uma estética romântica. Por esse motivo, as avaliações

\footnotetext{
${ }^{1}$ Universidade Federal do Rio Grande do Sul - UFRGS, Porto Alegre, Rio Grande do Sul, Brasil; https://orcid.org/0000-0002-3351-2139; rafael.brunhara@gmail.com
} 
sobre sua obra são muitas vezes díspares: Alcântara Machado, por exemplo, o chamará "romântico arrependido" (1936); Candido, por sua vez, em sua Formação, o definirá como um "romântico de primeira hora", considerando-o representante de uma geração "vacilante" que situou a estética e os lugares comuns do classicismo em clima romântico (2014, p. 369).

Pretendemos discutir que esta oscilação é conspícua na poesia de Gonçalves de Magalhães e que pode ser reveladora para uma compreensão mais adequada de seu poema Confederação dos Tamoios.

Assim, neste trabalho consideraremos certos aspectos da polêmica encetada por José de Alencar sobre a Confederação dos Tamoios seguindo de perto as proposições expressas por Saulo Neiva em seu artigo "Reler hoje a Confederação dos Tamoios?" (2017) mas, também, atendendo a seu convite naquele trabalho, propor uma leitura do poema que "o insira novamente na obra de Magalhães, mais do que na ruidosa polêmica que o envolveu" (2017, p.15). Indo nessa direção, este trabalho busca, num primeiro momento, explicitar o percurso e programa poético da obra de Gonçalves de Magalhães, e em seguida debater exemplos da Confederação que ali a inserem e que delineiam uma concepção particular de poesia épica, em contrário àquelas alardeadas na polêmica suscitada por José de Alencar acerca do poema.

A tentativa de uma epopeia brasileira durante o Romantismo já havia sido empreendida outrora, com a obra de Teixeira e Souza, a Independência do Brasil. O primeiro volume data de 1847, e o segundo, de 1855, mas a obra já era gestada desde o início dos anos 40, como afirma o autor no prefácio ao primeiro volume $(1847$, p.16).

O infortúnio da obra, pouco lembrada, se deve menos por seus méritos poéticos do que por sua inadequação a um programa poético-político que grassava nos primeiros anos do Romantismo brasileiro. Quanto à forma, o poema segue os elementos característicos do gênero épico: seu herói é Pedro, e o maravilhoso está presente na representação de anjos, demônios e personificações, como, por exemplo, o Despotismo e a Anarquia, que aqui aparecem no lugar de divindades pagãs numa elaboração que antes remete a Tasso e sua Jerusalém Liberta do que aos Lusíadas de Camões. Aproxima-se de Camões, contudo, pelo emprego do decassílabo e da oitava rima. Desse modo, o modelo formal é camoniano, mas não a matéria, que é rigorosamente contemporânea e oferece uma representação distinta do maravilhoso, não adotando o elemento mitológico nem mesmo como figura poética.

Quando Teixeira e Souza se permite explorar uma tópica da epopeia antiga, a descida aos infernos, nos Cantos V e VI, representa o Despotismo, inimigo do Brasil, a mobilizar as potências infernais contra a nação. Lá incorpora o imaginário pagão apenas como catálogo, outro recurso formal da epopeia (Canto VI, estâncias 26 e 27):

\section{XXVI}

Per entre as trevas denegrida assoma

A turba, que surgira desse Abysmo,

A qual á velha Grécia, e antiga Roma

Já levara o fallaz polyteismo;

Ninguém calcular pôde a vasta somma

Dos deuses, que adorara o gentilismo!...

Creu-se que o num'ro seu o Olympo enchia.

A cujo peso Atlante succumbia!

\section{XXVII}

São esses os que foram n'outra edade

Rhea; Juno (dos numes soberana);

Saturno; Jove (a excelsa divindade); 
Pallas; Astrea; Ceres; e Dianna;

Thetis; e dos amores a deidade;

Marte (da guerra divindade insana);

Neptuno; Apollo; Baccho; Hermes; Summano;

Esculapio; Bellona; Hebe; Vulcano:

(Teixeira e Souza, 1847, p.256-257)

Como mostra Paulo Franchetti (2007, p. 91-92), o poema é rejeitado, e seu desprestígio, malgrado seus dotes poéticos modestos, se deve antes ao empenho de Pedro II em favorecer os intelectuais do Instituto Histórico Geográfico Brasileiro, que apregoavam a necessidade de estudos e obras literárias dedicadas aos indígenas brasileiros. De fato, datava já de 1836 a publicação da primeira edição da revista Nitheroy, em que Gonçalves de Magalhaes publica o Ensaio sobre a História da Literatura Brasileira - Estudo Preliminar, que será como que um primeiro manifesto romântico brasileiro. Em passagem conhecida, enfatiza o desejo de descolamento de Portugal e de uma poesia fundada na mitologia, em busca de uma moralidade poética "que empluma as asas ao Gênio" (Magalhães,1836, p.148):

Com a poesia vieram todos os Deoses do paganismo, espalharam-se pelo Brasil, e dos céos, das florestas e dos rios se apoderaram. A Poesia do Brasil não é uma indígena civilisada, é uma Grega, vestida à Francesa, e à Portuguesa, e climatisada no Brasil. (Magalhães, 1836, p. 146).

Os poetas, agora, devem inspirar sua imaginação no Brasil, no indígena, e para tanto Magalhães se vale da ideia advogada por Schiller no ideário do Romantismo alemão: é o Gênio do poeta - sua inspiração original - que passa a ser a única coisa a regrar a arte, que deve se libertar dos modelos clássicos pré-determinados e seguir apenas as inspirações de alma. Harmoniza-se perfeitamente à ideia de gênio a intenção de explorar temas que caracterizem o novo estatuto do Brasil independente, atestando certa tendência antilusitanista das letras brasileiras do período na tentativa de cravar sua nacionalidade.

Mas se esta premissa se dá inovadora quanto à matéria, sua forma ainda é clássica: embora se busque um novo regramento formal, predomina ainda um regime representativo, ou mimético, que entenderá a arte como a imitação da natureza ou de modelos. Tal concepção estará, a nosso ver, no cerne da composição da Confederação dos Tamoios, e se mostra numa oscilação entre os motivos românticos e a moldura clássica, a meio caminho da imitação dos modelos e da inspiração romântica.

Esta dicotomia entre a noção de gênio e a exemplaridade dos modelos aparece em outro trecho do ensaio, este menos citado. Nele, Magalhães condena a imitação servil dos antigos, os preceitos clássicos de imitação que paralisam o gênio, mas ao mesmo tempo recomenda o seu estudo, mostrando a vigência dos modelos. Seu manifesto romântico é sobretudo conservador:

e si até hoje a nossa poesia não oferece um caracter inteiramente novo e particular, é que os Poetas, dominados pelos preceitos, atados pela imitação dos Antigos, que como diz Pope, é imitar mesmo a Natureza (como si a natureza se ostentasse sempre a mesma nas regioens polares, e nos Trópicos, e diversos sendo os costumes, as leis, e as crenças, só a poesia não partilhasse essa diversidade) não tiveram bastante força para despojarem-se do jugo dessas leis, as mais das vezes arbitrárias, da quelles, que se arrogam o direito de torturar o Gênio, arvorando-se Legisladores do Parnaso. Depois que Homero, inspirado pelo seu Gênio, sem apôio de alheia crítica, elevou-se à grandeza 
da Epopeia, creação sua, e Píndaro pelo mesmo caminho à sublimidade da Lírica, vieram então, os críticos, e estabeleceram as regras. Convém estudar os Antigos, e os modelos dos que nas diversas compoziçoens poéticas se avantajaram, mas não escravizar-se. (Magalhães,1836, p. 158).

Ao mesmo tempo que teorizou o Romantismo, lançou-se à sua prática. Interessa-nos nesse sentido o prefácio de seu livro de poemas Suspiros Poéticos e Saudades, "Lede", que tenta resumir os expedientes da arte romântica, mas, ao fazê-lo, é revelador de uma oscilação entre o clássico e romântico. Como nota Manuel Bandeira (2009, p.46) em sua Apresentação da Literatura Brasileira, se Magalhães "despediu-se das ficções de Homero não despediu-se totalmente da velha retórica":

Pede o uso que se dê um prólogo ao Livro, como um pórtico ao edifício, e como este deve indicar per sua construcção a que Divindade se consagra o Templo, assim deve aquelle designar o caracter da obra. Sancto uso, de que nos aproveitamos (...) (Magalhães, 1836, p.1).

O primeiro parágrafo alude a um modelo a ser imitado, à adequação a um gênero ou ao uso: "Pede o uso que se dê um prólogo ao livro". A poesia é equiparada ao edifício, perene, resgatando a tópica clássica do Exegi Monumentum ${ }^{2}$ por um lado a imagética é pagã: deve-se indicar "a qual divindade o templo se consagra", por outro, o prefácio, de "Santo uso", remete à esfera católica. Magalhães propõe, neste primeiro parágrafo de "Lede", uma reforma, sim, mas uma reforma prudente do edifício neoclássico. Ele prossegue:

É um livro de poesias escriptas segundo as impressoens dos logares; ora sentado entre as ruínas da antiga Roma, meditando sobre a sorte dos impérios; ora no cimo dos Alpes, a imaginação vagando no infinito, como um átomo no espaço; ora na gothica catedral, admirando a grandeza de Deos, ora entre os cyprestes, que espalham suas sombras sobre os túmulos; ora enfim reflectindo sobre a sorte da Pátria, sobre as paixoens dos homens, sobre o nada da vida. São Poesias de um peregrino, variadas como as scenas da natureza, diversas como as phases da vida, mas que se harmonisam pela unidade do pensamento, e que se ligam pelos annéis de uma cadeia. Poesias d'alma, e do coração, e que só pela alma, e o coração, devem ser julgadas. (Magalhães, 1836. p.2).

Seus poemas serão "escritos segundo a impressão dos lugares": é a imersão num mundo mediado pelo Eu, o território por excelência da subjetividade romântica; o poeta medita sobre a fugacidade de tudo ("nas ruínas da Antiga Roma") e sobre o sublime (ora terrível, "no cimo dos Alpes", ora magnífico, "a gótica catedral"); mas, ao mesmo tempo, demonstra preocupação com a unidade da obra (tudo se harmoniza pela unidade do pensamento), uma recaída neoclássica que logo é contraposta com outra imagem: "são poemas da alma e do coração, e que só pela alma, e o coração, devem ser julgadas". Magalhães tenciona que seus poemas sejam um suspiro que se harmonize com o suspiro de seu leitor, retomando a ideia de uma identificação subjetiva e quase inapreensível.

\footnotetext{
${ }^{2}$ Os primeiros vestígios desta tópica, consagrada por Horácio em sua Ode 3.30, já ocorrem na Ode Olímpica VI do poeta grego tardo-arcaico Píndaro, que compara a abertura de seu poema a um pórtico com colunas de ouro: áureas colocando no bem-/construído pórtico da câmara/ as colunas, como que mirífico palácio/construamos. Início da obra, deve-se/dar-lhe uma fronte longiluzente”.
} 
A partir daí, o clássico vai se tornando romântico: seu livro deixará de ser o edifício referido no início do prefácio para tornar-se "folhas que lançamos hoje aos pés" (Magalhães, 1836, p.3) ou ainda "folha no meio da floresta batida pelos ventos do inverno" (Magalhães, 1836, p.8-9). A ideia clássica de perenidade da obra alterna-se com imagens de sua fugacidade e efemeridade que constituem um dos temas favoritos do Romantismo. Embora o livro seja um suspiro - um eco no domínio do inefável que corresponde à manifestação indivisa da interioridade do poeta - Magalhães afirmará, racionalmente, que "para bem se avaliar esta obra, três cousas releva notar-se: o fim, o gênero e a forma" (Magalhães, 1836, p.3), remetendo-nos a um modelo clássico de produção genérica, no qual cada circunstância possui o seu gênero poético específico, formalmente estruturado e objetivado.

Parecia necessário indicar os ditames desta estética que desembarcava no Brasil e que na Europa já começava a ser superada, mas ao listar em tom acelerado as tópicas românticas que se desenvolveram apenas gradualmente na Europa, tornam-se patentes as oscilações de Magalhães entre a linguagem neoclássica vigente e a recém-chegada romântica.

Esta incerteza e oscilação será admitida trinta anos depois; Magalhães chamará "desalinho" ao lirismo romântico, afirmando que sua única lei é a desordem, e situará sua obra no entrelugar do clássico e do romântico. É o que expressa em 1865, na publicação de suas Tragédias, apenas um ano depois da segunda edição de seus Tamoios. Talvez já escaldado pela polêmica contra sua epopeia, adverte, nas Tragédias:

Frios censores, críticos impassíveis, juizes parciaes e imparciaes, amigos e inimigos, a vós me entrego. Não faltarão accusaçoes em todos os gêneros. Talvez tenham razão, sobretudo si quizerem medir esta obra com o compasso de Aristóteles e de Horacio, ou vel-a com o prisma dos Românticos. Eu não sigo nem o rigor dos Clássicos, nem o desalinho dos segundos; não vendo verdade absoluta em nenhum dos systemas, faço as devidas concessões a ambos; ou antes, faço o que entendo, e o que posso. (Magalhães, 1865, p. 7).

Parecem-nos suficientes estes argumentos para situar a Confedereção dos Tamoios no seio do projeto poético de Gonçalves de Magalhães e deste "Romantismo de primeira hora". Esta concepção de sua obra elide em boa parte a crítica que recaiu sobre o poema na polêmica criada por José de Alencar com as suas Cartas sobre a Confederação dos Tamoios. Como nos mostra Neiva (2017, p. 7-8), Alencar centra sua crítica em dois aspectos: a inépcia técnica de Gonçalves de Magalhães e a impropriedade do poema como epopeia. O estudioso observa que essa impropriedade parte de um corolário assumido por Alencar de que a epopeia seria um gênero caduco. Caduco porque não é mais possível, neste novo momento literário, adotar estritamente as regras inspiradas pelos modelos. É por não seguir os modelos e por usar na épica um arcabouço de imagens próprios de outros gêneros - revive-se aí a ideia do decorum clássico - que Magalhães será criticado. Cito os excertos, já mencionados por Neiva (2017, p. 8):

Perguntaria se não é extravagante que um poeta, destinando-se a cantar um assumpto heróico, invoque para este fim o "sol que esmalta as pétalas das flôres", como faria um autor de bucólicas e de idylios? [...] [...] A invocação do poema do sr. Magalhães, por qualquer lado que a consideremos, não satisfaz; como arte, como fórmula da epopéa, é contra as regras e exemplos dos mestres. (Alencar, 1856, p. 65-66).

Neiva (2017, p. 9) mostra que a concepção de épica de Magalhães dialoga com as concepções de épica do passado e é mais dinâmica do que a visão alencariana. Na advertência 
à segunda edição de sua epopeia, Magalhães concebe a épica como "encerrando todos os gêneros de poesia" (2008, p. 855) - uma visão renascentista - ao mesmo tempo em que visa à atualização do gênero: afirma abandonar a oitava rima camoniana, medida consagrada para o gênero, posto que demais convencional e inadequada ao gosto da época.

Acrescentamos às teses de Neiva que Magalhães opera essa renovação da epopeia, propondo objetivamente uma interação entre a matéria de seu poema e o substrato e a imagética clássicas, nunca os abandonando de todo, mas antes dialogando com eles: ${ }^{3}$ ainda são os estertores de uma poética da representação, que concebe a arte como imitação, mas esta imitação é, agora, toda nova, desprendida dos modelos europeus e injetada por um clima de nacionalidade.

Um exemplo deste expediente, na Confederação, está no uso do símile; recurso retóricopoético determinante na epopeia clássica, oportuniza para Magalhães comparar figuras do arcabouço clássico com a originalidade de cenas, personagens e paisagens brasileiras. É o caso do símile que caracteriza o herói do poema, Aimbire em sua primeira aparição (II, v. 48-53). Lá, o índio é comparado, respectivamente, a Hércules, ao deus Marte e à estatuária grega de Fídias, numa profusão de tópicas greco-latinas:

De vulto hercúleo, soberano o porte,

Olhar dominador, severo o rosto,

Bela estátua de bronze parecia,

Qual a de Marte modelara um Fídias.

(Magalhães, 2008, p. 882).

O Amazonas, nos versos 60 a 63 do primeiro canto:

Ressupino gigante se afigura,

Qual outro Briaréu, mas verdadeiro,

Que estende os braços para arcar a terra!

(Magalhães, 2008, p. 861).

Que seria programático pôr lado a lado tais imagens a fim de evidenciar suas novas intenções estéticas já nos diz a própria obra, revelando o jogo que parece predominar nos poemas de Magalhães (I, v. 132-138):

Oh vós da Grécia deleitosos campos

Onde o Alfeu e o Eurotas serpenteiam,

E em cujas margens dríades habitam!

Montes, que dais abrigo em vossos topes,

De loureiros à sombra, às castas Musas;

Vós não assoberbais a majestade

Destes montes brasílios, destes bosques!

(Magalhães, 2008, p.863).

\footnotetext{
${ }^{3}$ Isso fica evidente na figura de outros poetas que Magalhães toma por mentores. Souza Caldas, chamado por ele "primeiro dos nossos líricos" (Magalhães, 1836, p. 4), reitera, no conteúdo, a temática religiosa ao apropriar-se de modos de expressão bíblicas e rompe com a imaginação árcade; no entanto, transpõe os salmos em formas fixas, como a cantata e a ode.
} 
Esse diálogo entre originalidade e modelo Magalhães encontrará não só em antecessores árcades que retrataram o índio, como Santa Rita Durão e, sobretudo, Basílio da Gama, que, contudo, ele não refere diretamente, ${ }^{4}$ mas também em contemporâneos românticos, sobretudo Odorico Mendes, este sim, referido, como veremos agora.

Apenas um ano antes da publicação da Confedereção dos Tamoios, vinha à lume a Eneida Brasileira, em 1854; o epíteto não era fortuito. Com este título, Odorico não só enfatizava seu feito de verter todo o Virgílio em português (projeto que seria concluído em 1858), mas também marcava um posicionamento que distinguia sua Eneida daquela dos tradutores lusitanos, João Franco Barreto (no século XVII, que adotara a oitava rima e léxico camoniano) e José Victorino Barreto Feio, já no XIX.

É possível que a tradução de Odorico possa ter influído na conceituação da epopeia de Magalhães, como se pode depreender de ensaio publicado por Magalhães na Revista do Instituto Histórico Geográfico Brasileiro do primeiro trimestre de 1860. Nela, Magalhães toma Odorico como auctoritas da epopeia brasileira, em um tom que aparenta ser uma réplica velada à polêmica de cinco anos atrás:

Os feitos dos indígenas oferecem argumento simpático à nossa poesia nacional. E como bem notou o Sr. Odorico Mendes: os selvagens, rudes e de costumes quase homéricos, podem prestar belos quadros à epopeia. O parecer de tão abalizado crítico, que nos deu Virgílio em português, e luta para interpretar Homero, é de tanto peso, que decide só por si qualquer dúvida. (Magalhães, 1860, p. 63).

O latinista brasileiro Paulo Sérgio de Vasconcelos (2007, p. 39), em análise das traduções de José Vitorino Barreto Feio e de Odorico Mendes, observa que, embora ambos os tradutores por vezes "filtrem Virgílio pelo viés camoniano", Odorico "se impregna do estilo virgiliano e escreve à maneira virgiliana, empregando certas características do estilo do poeta latino", como arcaísmos, hipérbatos e compostos poéticos. O pesquisador Brunno Vieira (2010, p. 144) mostra como, em passos da epopeia de Magalhães, há alusões à Eneida odoricana em chave intertextual. Ele cita, como exemplo, trecho que marca o início da narração na Confederação dos Tamoios (I, vv. 46-48) - "Baliza natural ao Norte avulta / O das águas gigante caudaloso, / Que pela terra alarga-se vastíssimo." (Magalhães, 2008, p. 860) - que são comparados aos versos 20-22 da Eneida Brasileira de Odorico Mendes: "Colônia Tíria no ultramar, Cartago, / Do Ítalo Tibre contraposta às fozes / Houve, possante empório, vastíssimo." (Mendes, 1854, p.7).

Segundo Vieira, ambas as obras compartilham de recursos poéticos e retóricos que remetem a uma herança latinizante, se não mais propriamente virgiliana:

O início da epopeia e da tradução brasileira são correlatos. Notem-se a digressão geográfica (lá o Amazonas, cá Cartago), o hipérbato latinizante ("o das águas gigante caudaloso" // "do ítalo Tibre contraposta às fozes"), a amplificação na descrição (a concatenação de epítetos e adjetivos e a coincidência dos superlativos finais

\footnotetext{
${ }^{4}$ Embora Alencar perceba argutamente as imitações a estes poetas nas suas Cartas sobre a Confederação dos Tamoios. Quanto a Basílio da Gama, compara explicitamente seus versos a versos de Magalhães e à representação do herói em ambas as obras: "Na descripção que se segue dos outros guerreiros há muitos pontos em que o poema se assemelha ao Uraguay" (ALENCAR, 1856, p. 20) A referência a Durão está no modo como Magalhães imita a mesma matéria do poeta do Caramuru, as lendas e tradições indígenas: "esses mesmos costumes e lendas achãose, com alguma diferença de palavras, no Caramurú de Santa Rita Durão, o qual as bebeu nos nossos chronistas, d'onde as tirou o Sr. Magalhães" (1856, p. 45).
} 
"vastíssimo" e "aspérrimo"), a economia nos artigos no primeiro verso que deixa lapidar o português. (Vieira, 2010, p. 145).

Uma comparação, também citada pelo pesquisador (2010, p. 145, n. 14), com a tradução portuguesa de José Vitorino Barreto Feio, igualmente do século XIX, pode elucidar a proximidade entre Magalhães e Mendes:

Longe da foz do Tibre, olhando a Itália,

Uma cidade antiga houve, Cartago:

Colônia foi de Tírios; opulenta,

E na escola da guerra endurecida.

(Feio, 1846, p. 4).

Mas não é só pela linguagem e pela forma que se nota a relação com a Eneida. Ela também ocorre na reatualização ou emulação de lugares-comuns da epopeia. No Canto VI da Eneida, Virgílio imita uma cena já vista na Odisseia de Homero: a descida aos infernos. Neste episódio, Eneias reencontra o pai, Anquises, que lhe mostra as almas que encarnarão nos corpos dos heróis romanos ainda por nascer. É o momento em que Virgílio tece um elogio à Roma, mostrando como será grandioso o futuro dos romanos, herdeiros de Troia (Eneida Brasileira, Canto VI, vv. 778-781):

Eia, a glória que os Dárdanos espera,

Do ítalo tronco os descendentes nossos,

Que a fama illustrarão de seus maiores,

Hei de explicar-te, e aprenderá teus fados.

(Mendes, 1854, p.207).

Nesse momento, Eneias tem uma visão de seu longínquo descendente, Otaviano Augusto, que restituirá paz comparável à era de ouro, os "satúrnios séculos dourados" (Eneida Brasileira, Canto VI, vv. 816-819):

Eis, eis o promettido, Augusto César,

Diva estirpe, varão que ao Lácio antigo

Há-de os Satúrnios séculos dourados

restituir $(\ldots)$

(Mendes, 1854, p. 208).

Não há propriamente uma "descida aos infernos" na Confederação dos Tamoios. Mas assim como Eneias vê o futuro glorioso de seu povo configurado na Roma que é a dos tempos de Virgílio, na Confederação dos Tamoios, Magalhães também acenará aos heróis de sua epopeia um futuro de glórias.

Depois de um confronto com o cacique Tibiriçá, o herói tamoio Jagoanharo recebe em sonho a visita de São Sebastião, que lhe dá uma visão do futuro. O santo mostra, neste futuro, entre outros atos, a fundação do Rio de Janeiro (onde culmina a narrativa da Confederação), a independência do Brasil e o fim do conflito narrado no poema, tecendo um elogio aos imperadores brasileiros e à cristandade. Seguem-se, assim, os moldes de Virgílio, pois o que é futuro no entrecho da narrativa é, extradiegeticamente, o elogio do presente por meio da elaboração da matéria do passado. Desse modo, são retratados Pedro I, louvado como um herói pacificador aos moldes do Augusto César de Virgílio, e Andrada - José Bonifácio de Andrada e Silva, patriarca da independência (Canto VI, vv. 224-227): 
Ei-lo, egrégio mancebo de alto porte, A quem glória imortal o céu destina, Dos filhos do Brasil já ladeado,

E desse sábio Andrada, que se ufana

Co'os ilustres irmãos de ter nas veias

Sangue de Tib'riçá, e dos tamoios.

(MAGALHÃES, 2008, p. 976).

Se a Confederação dos Tamoios termina com a queda dos índios perante o inimigo, por outro lado, na figura de Andrada, que "se ufana de ter nas veias o sangue de Tibiriçá e dos tamoios", se entrevê uma reconciliação futura, constituindo um passado nacional, do mesmo modo que ocorre na Eneida de Virgílio, quando o herói troiano, Eneias, funda uma nova cidade que aplacará a ira até mesmo de deuses antes inimigos.

Como conclusão, dois elementos permitem resgatar A Confedereção dos Tamoios e chamá-la "modelar"; primeiro, ao que já aludimos, a plena adequação da obra ao programa poético de Magalhães, que não só concebe a épica como dinâmica (Neiva, 2017, p. 9), mas que também busca a síntese dos arcabouços formal e imagético clássicos com temas de cunho nacional, num claro esforço por emulação, sem abandoná-los de todo. Esta parece ser a resposta encontrada por Magalhães para lidar com a adequação das formas antigas diante da emergente estética romântica.

Em segundo lugar, observada a importância e autoridade de Odorico Mendes, notadas pelo próprio Magalhães, para a concepção de epopeia, pode-se pensar numa filiação do poeta brasileiro a um molde virgiliano, ou a uma certa "vertente latinizante" esquecida da poesia brasileira, mas que, como define o estudioso Paulo Franchetti, trata-se de

Uma vertente que talvez só agora possa ser encarada de modo compreensivo, com a queda da hegemonia do padrão de gosto modernista e com o consequente esbatimento do vetor teleológico da descrição histórica elaborada em meados do século $\mathrm{XX}$, que apagou ou como monstruosidade ou apanhado de tolices, tudo aquilo que se afastava da linha ideal de progresso em direção à coloquialidade expressiva posta a serviço da investigação ou do retrato da vida social. (FRANCHETTI, 2008, p. 1103).

Parecem-me importantes estes elementos, para que A Confederação dos Tamoios possa ser mais considerada e estudada, encaminhando-a para além das polêmicas que nutriram a sua recepção. 


\section{REFERÊNCIAS}

ALENCAR, José de. Cartas sobre a Confederação dos Tamoios. Rio de Janeiro: Imprensa Tipográfica Nacional, 1856.

BANDEIRA, Manuel. Apresentação da poesia brasileira. São Paulo: Cosac Naify, 2009.

CANDIDO, Antonio. Formação da Literatura Brasileira: momentos decisivos. Rio de Janeiro: Ouro sobre Azul, 2014.

FEIO, José Victorino Barreto. Eneida de Virgílio Maro. Tomo I. Lisboa: Imprensa Nacional, 1846.

FRANCHETTI, Paulo. O triunfo do Romantismo: indianismo e estilização épica em Gonçalves Dias. In: TEIXEIRA, I., org. Épicos: Prosopopeia, O Uraguai, Caramuru, Vila Rica, A confederação dos Tamoios, I-Juca-Pirama. São Paulo: Imprensa Oficial, 2008.

FRANCHETTI, Paulo. Estudos de Literatura Brasileira e Portuguesa. São Paulo: Ateliê, 2007.

MACHADO, Antônio Castilho de Alcântara. Gonçalves de Magalhães ou o romântico arrependido. São Paulo: Edições acadêmicas Saraiva, 1936.

MAGALHÃES, Gonçalves de. A Confedereção dos Tamoios. In: TEIXEIRA, I., org. Épicos: Prosopopeia, O Uraguai, Caramuru, Vila Rica, A confederação dos Tamoios, I-Juca-Pirama. São Paulo: Imprensa Oficial, 2008.

MAGALHÃES, Gonçalves de. Ensaio sobre a História da Literatura Brasileira - Estudo Preliminar. Nitheroy, Revista Brasiliense, Rio de Janeiro, tomo I, n.1, 1836, p. 132-159.

MAGALHÃES, Gonçalves de. Os indígenas do Brasil perante a História. Revista do Instituto Histórico Geográfico Brasileiro, Rio de Janeiro, tomo XXIII, 1860, p. 3-111.

MAGALHÃES, Gonçalves de. Suspiros poéticos e saudades. Rio de Janeiro: Casa do Senhor João Pedro da Veiga. Paris: Dauvin et Fontaine Libraires, 1836.

MAGALHÃES, Gonçalves de. Tragédias. Rio de Janeiro: Garnier, 1865.

MENDES, Manuel Odorico. Eneida brasileira ou Tradução poética da epopéia de Públio Virgílio Maro. Paris, França: Rignoux, Imprimeur, 1854.

NEIVA, Saulo. Reler hoje a Confederação dos Tamoios? Brasil/Brazil, vol. 30, n. 55, 2017, p. $1-17$.

SOUZA, Antônio Gonçalves Teixeira e. A Independência do Brasil. Tomo I. Rio de Janeiro: Tip. Imparcial de Francisco de Paula Brito, 1847.

VASCONCELOS, Paulo Sérgio. Duas traduções poéticas da Eneida. In: MARTINHO, Marcos, org. II Simpósio de Estudos Clássicos da USP. São Paulo: Humanitas, 2007. 
VIEIRA, Brunno Vinícius Gonçalves. Recepção de Odorico: (a)casos de crítica de tradução no século XIX. Phaos: Revista de Estudos Clássicos, n. 10, 2010, pp. 139-154.

Rafael Brunhara - Doutor em Letras pela Universidade de São Paulo, é professor adjunto na Universidade Federal do Rio Grande do Sul. É autor de "O fragmento de Télefo e a fuga em Arquíloco" (2018), "Paideia na 'lírica' grega arcaica: a poesia elegíaca e a mélica" e de "Visualizando a guerra no mundo anrigo: o caso de Homero e da Lírica Grega" (2016), entre outras publicações. É membro da equipe de pesquisadores do projeto Discurso da épica nas culturas lusófonas do século XIX - Probral Capes/DAAD 2018-2021. Orcid 0000-0002-33512139.

Submetido em $11 / 02 / 2020$

Aceito em 14/04/2020 